\section{BOOK REVIEW}

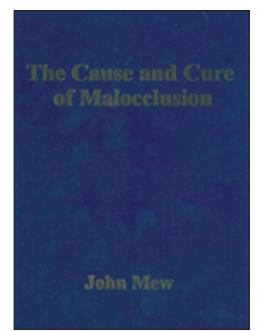

THE CAUSE

AND CURE OF MALOCCLUSION

J. Mew

John Mew

price £140.00; pp 354

ISBN N/A

The cause and cure of malocclusion is a self-published title that hopes to provide an alternative opinion and approach to conventional orthodontics. The book focuses on the work of the author John Mew and his orthotropic treatment of malocclusion based on 'growth guidance' and staged functional appliances.

The text is intended for people with a keen interest in the specialist area and for those who have substantial prior knowledge as it covers a wide range of topics, often in parallel. Consequently, I would categorise this publication as a further-interest book rather than a core text offering clear and concise information.

The early chapters aim to lead the reader through the various causes of malocclusion and outline how orthotropic treatment leads to superior results compared to conventional orthodontics. Being written in extensive prose, often recanting first hand discussions or publications, the initial chapters can lose structure with diagrams that are often heavily annotated and photographs that tend to add little to the topic.

The remaining sections discuss the complex approach of orthotropics with regard to 'reading the face', diagnosis and treatment planning. Mew argues the use of functional appliances (Bioblock) in treating the majority of skeletal abnormalities reduces the need for extractions and surgery. He concludes with a chapter devoted to his supporting clinical research. The description of orthotropics for routine treatments and its application for difficult cases will be uncommon to those who have read more orthodox orthodontic texts.

The book also includes three chapters of the author's views on the established orthodontic specialty and his career, personal life, heritage and various inventions (including the folding ladder and sink waste disposal unit); an uncommon addition to modern textbooks but that which sets the tone of the publication.

In conclusion, this book addresses a very specific field of interest mixed with alternative nomenclature. Due to its unconventional approach the text will have limited relevance to the general practitioner or dental student, but specialists will be able to reach their own conclusions with regards to Mew's alternative approaches to malocclusion.

A. STIRRUP

\title{
'GATEWAY TO ASIA' CONFERENCE BREAKS RECORDS
}

The eighth IDEM Singapore (International Dental Exhibition and Meeting) held on 4-6 April 2014 was a record-breaking success, with more than 500 exhibitors from 38 countries and 7,842 participants from 61 countries.

The IDEM Singapore trade fair was the largest staged at the Suntec Singapore Convention and Exhibition Centre since it was refurbished, and the first ever to fill both floors of exhibition space covering $16,000 \mathrm{~m}^{2}$.

IDEM Singapore is increasingly seen as the gateway to Asia for dental manufacturers and distributors wishing to break into Asian markets.

A scientific programme at IDEM with the theme 'Dentistry - the future is now' featured 45 different sessions and 36 international speakers.

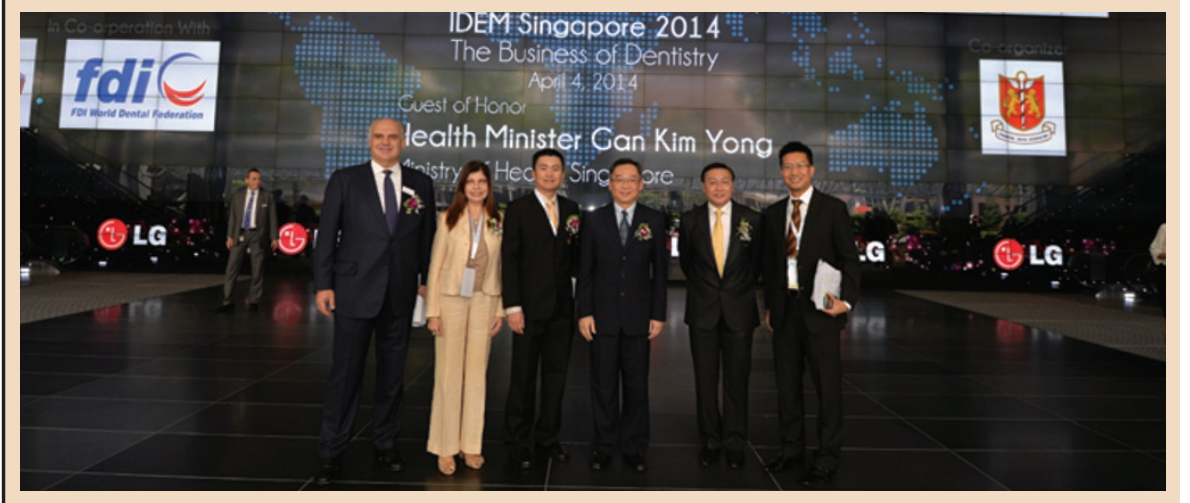

